\title{
Boswellia serrata Extract
}

National Cancer Institute

\section{Source}

National Cancer Institute. Boswellia serrata Extract. NCI Thesaurus. Code C49089.

A standardized extract derived from the plant Boswellia serrata of the family

Burseraceae with anti-inflammatory activity. Boswellia serrata extract contains terpenoid boswellic acids, which are potent inhibitors of 5-lipoxygenase activity and, so, leukotriene synthesis. 